\title{
Developing learning materials supporting teachers' understanding on mathematics problem-solving knowledge for teaching
}

\author{
Tatag Yuli Eko Siswono, Ahmad Wahidul Kohar, Sugi Hartono, Rooselyna Ekawati, Pradnyo Wijayanti \\ Faculty of Mathematics and Natural Science, Universitas Negeri Surabaya \\ Surabaya, Indonesia \\ Corresponding email: tatagsiswono@unesa.ac.id
}

\begin{abstract}
This study aims to develop a set of learning materials supporting teachers' understanding of mathematics problem-solving knowledge for teaching (MPSKT). The MPSKT implemented in the learning materials consist of problem-solving content knowledge (PSCK) (knowledge of problems, nature of problem-solving, problem-posing), pedagogical problem-solving knowledge (PPSK) (knowledge of students as problem solvers, instructional practice for problem-solving), and affective factors and beliefs (beliefs about nature of mathematics, mathematics teaching, and mathematics learning). The learning materials, consisting of lesson plan and teaching book, were developed by following two stages, i.e. preliminary stage and prototyping using formative evaluation: one-to-one, self-evaluation, small group, and field test. There were 41 teachers involved to examine the validity, practicality, and effectiveness of the learning materials. Results indicate that prototype of the learning materials were revised along the formative evaluation stages, in which it was proved valid and practical according to the revision based on experts' review and teachers' suggestion. Also, it was effective to improve teachers' understanding of MPSKT and beliefs about teaching and learning mathematics. In the future studies, we encouraged to develop learning materials which include these two components more explicitly as well as a more comprehensive and complete component of MPSKT characterizing a complex network of interdependent knowledge among the components.
\end{abstract}

Keywords-mathematics problem-solving knowledge for teaching; preservice teacher; development study

\section{INTRODUCTION (HEADING 1)}

Studies on mathematical problem solving become an intensive view of experts mainly dealing with essential questions regarding the teaching and learning of mathematics. While the focus has been given more on the students in the early years, a body of studies directly or indirectly offering recommendations of the knowledge teachers should hold to teach problem-solving is required to be developed. Therefore, in order to have a broader insight on the needs of teacher related to problemsolving, Chapman [1] has proposed the so called 'mathematics problem-solving knowledge for teaching' (MPSKT), i.e. the knowledge needed to effectively teach problem solving. To facilitate teachers learn MPSKT, it is required a set of learning materials which help them learn MPSKT.
Chapman [1] describes the categories of problem solving knowledge into three main categories, namely problem solving content knowledge, pedagogical problem-solving knowledge, and knowledge of affective factors related to problem-solving teaching. Problem-solving content knowledge includes four things. First, knowledge of the meaning of the problem. Teachers need to understand issues based on their structure and goals in order to guide students find solutions including an understanding of the types of tasks, such as cognitive tasks; tasks with the potential to develop mathematical creativity in problem solving; tasks that demand problems that generally allow for various problem-solving strategies; rich math tasks, and problem-based tasks are open. Second, knowledge of proficiency in problem solving. For this, Chapman describes this category to 4 , namely (1) conceptual understanding of mathematical concepts, procedures and relationships, (2) an understanding of heuristic strategies and special strategies and when and how to use them in solving math problems, (3) the ability to think logically and understanding the reflection on self-awareness, monitoring and control, and self-cognitive control during the problem-solving process; and (4) having confidence in math, problem solving, and problem solving skills that can support motivation and confidence.

Third, knowledge of problem solving. This knowledge is necessary, for example, to understand that problem solving is viewed not only as a process but also as a way of thinking. This understanding, as Chapman discloses, will influence a teacher's perspective in building a model of understanding of the problem-solving process. Regardless of the problem-solving model being studied, Chapman asserts that teachers need to have conceptual and procedural understanding of the problemsolving models in order to understand the stages required by a problem solver and the thinking process involved in finding the solution of the current problem. Fourth, knowledge of math problem submission. This knowledge refers to Silver's [2] opinion which poses a posing problem as an activity to formulate a new problem and redefine the given problem. The second category of knowledge, the pedagogical knowledge of problem solving, consists of two subcategories. First, knowledge of students as problem solvers. In general, this 
knowledge includes knowledge of students' problem-solving difficulties, successful problem-solving characteristics, and the process of thinking in problem solving. Second, knowledge of teaching problem solving. In general, Chapman gives an idea of things that need to be understood. According to her, teachers need to understand the practice of learning that develops strategies and metacognition of students in solving problems and have strategic competence to face the challenges of problem solving during teaching. The third category of knowledge is knowledge of affective factors related to problem solving. This affective factor consists of motivation, interest, self-confidence, anxiety, perseverance, and student beliefs. Knowledge of these factors can help teachers to illustrate and support student problem-solving abilities based on findings that are appropriate to these factors.

All the abovementioned components of MPSKT become a new concern for not only support teachers' practice and knowedge-related understandings, but also improve teachers' belief from traditional to more constructivist view toward mathematics teaching and learning. Thus, to cover that needs, the need of providing learning materials supporting teachers' understanding of MPSKT is encouraged. Therefore, the aims of this study is to develop a set of learning materials (lesson plan completed with worksheets and teaching book.

\section{METHODS}

This research employ a development type study design that uses formative evaluation [3]. In this study, researchers developed the learning materials of basic mathematics concepts for prospective elementary school teachers who support the development of knowledge, beliefs, and practice of teaching. The stages of the research are preliminary stage and prototyping stage (formative evaluation) which includes self-evaluation, expert reviews and one-to-one, small group, and field test [4-5].

Tessmer [4] defines formative evaluation as a judgment of the strengths and weaknesses of the instruction in its development stages, for the purposes of revising the instruction to improve its effectiveness and appeal. From this definition it can be seen that in assessing the development of the teaching program, an assessment of the advantages and disadvantages of the program from each stage of development needs to be done to improve its effectiveness and attractiveness. The components involved in this evaluation are the designer of the teaching materials (in this case the researchers themselves), expert review, and the learner (in this case the prospective teacher and the class teacher). The involvement of this component will be explained in the research procedure. The subject of this research is the student of teacher candidate / primary school teacher of semester 1 who is taking the Basic Mathematics Concept Course of Graduate Program of Surabaya State University and an expert in the development of teaching materials of basic mathematics concept for elementary school. This research is carried out in stages starting from preliminary stage until the test field is conducted from July to December 2017. In detail, many subjects involved are 5 students (one-to-one), 3 experts (expert review), 6 students (small group), and 20 students (field test).

\section{RESULTS AND DISCUSSION}

\section{Development Process: Preliminary stage}

The development of instructional materials of the basic mathematical concepts in this research is through two stages: preliminary stage and prototyping. In the preliminary stage, the researcher conducted several activities: studying the literature on: (1) problem-solving knowledge for teaching, (2) beliefs about nature of mathematics, mathematics teaching, and mathematics learning [6-7]; (3) analyzing current curriculum relationships with the needs of the MPSKT developed in the learning materials and (4) designing instruments for measuring teachers' MPSKT, (6) determining instruments for experts and learners toward the teaching materials, (7) determining teachers whom would be involved as participants in prototyping stage, and (8) developing the procedures for conducting the research, and (9) examining teachers' initial beliefs about mathematics, mathematics teaching and learning.

The ninth step of preliminary stage was conducted on 41 elementary teachers who were studying at master degree of elementary education who have taken courses of basic mathematics concepts. They were asked to fill out a multiplechoice online questionnaire whose instruments were adopted from Siswono's [8-9] research on beliefs in mathematics, mathematics learning, and mathematics teaching, where the division of the type of philosophical beliefs in each of these categories was based on a summary of Beswick [6] (see table 2.3). The analysis of the questionnaire results is also based on Siswono et al's proposed model [See 8]. Results of this stage indicates there were 19 teachers, 5 teachers, and 17 teachers respectively having beliefs of Instrumentalist, Platonist, and problem solving in viewing the nature of mathematics. Regarding mathematics learning, there were 24 teacher indicated to have 'active construction understanding' beliefs, which corresponds to Platonist beliefs, 14 people having 'skill mastery' beliefs, and 3 teachers having 'autonomous exploration of teacher interest' beliefs. In viewing mathematics teaching, most teachers (22 people) view to teach with a learner focused type, which is most in line with problem solving view, followed by 16 teachers with 'content-understanding' view, which is in line with the Platonist view, and followed by 3 teachers with 'content-performance' view, which is in line with the Instrumentalist type. In general, these results show that there were still many subjects who do not generally have beliefs in line with problem solving, especially in categories of beliefs about nature of mathematics and mathematics learning. As such, this become another strong recommendation to develop learning materials improving such teachers' beliefs.

\section{Development Process: Prototyping stage}

At prototyping stage, formative evaluation consisting of self evaluation, expert review, one-to-one, small group, and field test were employed to examine the validity, practicality, and effectiveness of the learning materials. At the self evaluation stage, the researcher re-examined the initial prototype design while preparing the research instrument related to the development process. The study was conducted by checking the suitability of textbook material design, teacher activities both in 
terms of content, constructs, and language. At this stage is, the learning materials being developed is called prototype 1 . Meanwhile, the prepared research instruments are one-to-one validation sheet, expert review sheet, and questionnaire for small group and field test .

Prototype 1 as the revision from self-evaluation stage was then tested in one-to-one and expert review simultaneously. The one-to-one test was conducted to see the practicality of the developed materials. Information obtained from this activity is the teachers' comments about the clarity of the contents of the learning materials and the models of teachers' solution strategies on the problem written in the worksheet developed so that it can be known other alternative of solutions/strategies. Meanwhile, prototype 1 was given to some experts to be validated in terms of content, constructs, and languages. The result of these two processes was used to revise prototype 1 to prototype 2 . In one-to-one test, protoype 1 was given to them to work out some activities contained in the worksheet, then asked them to fill one-to-one questionnaire to confirm understanding students towards the intent and clarity of teaching materials. Based on the results of one-to-one, in general, the comments of the five one-to-one learners were related to (1) unclear images, (2) some less familiar terms, (3) less simple word editings, (4) learners' errors in comprehending the presentation of the learning materials, (5) the emergence of alternative solutions to problems in the worksheet, and (6) additional information about the objectives for all activities developed in the learning materials.

Furthermore, at the same time as the one-to-one test, the experts involved in the expert review also validate the prototype 1. Based on the expert review, the researcher revised the following teaching materials: correction of typo, the use of capital letters correct, more effective sentence writing, drawings are made more clearly legible, the addition of questions about the selection of learning sequences based on the type of beliefs on teaching mathematics. This is intended to add content about beliefs to math and learning that have not been included in previous prototypes, the revision of indicators of learning objectives to better describe the distribution of Bloom's taxonomy more evenly, especially at higher levels, reducing the number of questions in the worksheet 1 so adjusted to the allocation learning time, improvement of the format of the worksheet which should follow the standard of lesson plan, such as by attaching student identity, enlarging the answer column so that it matches the query request, explanation more explicitly about the time of worksheet use and explanation of orientation and perception on lesson plan, writing mathematical symbol with equation.

At the small group test, the researcher and the technician team applied the designed learning activities using the revised teaching materials based on the results of one-to-one validation and expert review. Small group trial aims to determine the response of subject students to the practicality of teaching materials that are reviewed from their opinions on the preparation of teaching book and worksheets as well as the validity of teaching materials viewed from the observation of learning activities. Furthermore, the researcher performs analysis of prototype 2 implementation with small group subject. It aims to obtain an overview of the various responses of subject students to the learning activities that are applied.

In the field test test, the lesson plan or the 2nd meeting is used as an example of the implementation of teaching materials developed in this study. The lesson plan and its supplementary instruments are part of revised prototype 3 based on revisions to small group results. Field tests started with learning as it was carried put in small groups, with only a larger number of subjects involved. After the subject completes the worksheets, the class discussion begins. The first thing to discuss is about the meaning of the problem. The findings of smallgroup and field test shows the same results in class discussions, where the majority of teachers assume that math problems are a problem for students if they feel difficulty to answer because at all never find the concept or mathematical procedures associated with the matter. This is evidenced by one of the student responses to the problem of straight line equations is a problem for elementary students.

The next discussion is about problem solving steps. In this subtopic, the majority of subjects present the steps that a problem solver should take to Polya's [10] steps, namely (1) understanding the problem, (2) preparing the plan / settlement strategy, (3) executing the settlement plan), and (4) check again. However, when discussing whether the sequence of mentioned steps of completion can always be used to solve other problems, the subject gives a uniform response, i.e 'not always' for various reasons. Among them is when solving the problem is not a story, the problem with a higher level of complexity, and when in these steps is not clear the direction of completion, it needs to be repeated again at certain stages. This latter view is the closest to the concept of solving dynamic problems as proposed by Mason [11], where it is quite possible that cyclical repetition occurs in problem-solving steps. The next discussion is related to problem solving strategies. The subject was given the following questions, then asked to identify what strategies the student was using to solve the problem and also to formulate other possible strategies.

$\begin{aligned} & \text { An elementary student shows the result of the sum of } 1+2 \\
& +3+4+5+6+7+8+9+10+11+12+13+14+15\end{aligned}$
\begin{tabular}{|c|l|l|}
\hline numbers by first creating a table like the following. \\
\hline $1+2=3$ & Hypothesis & Notes \\
\hline $\begin{array}{l}3 \text { is obtained } \\
\text { from } \frac{2 x 3}{2}=3\end{array}$ & $\begin{array}{l}2 \text { is the last } \\
\text { number and } \\
\text { continued with } \\
\text { the next 3 digits }\end{array}$ \\
\hline $1+2+3=6$ & $\begin{array}{l}3 \text { is the last } \\
\text { number obtained and } \\
\text { from } \frac{3 x 4}{2}=6\end{array}$ & $\begin{array}{l}\text { continued with } \\
\text { the next 4 digits }\end{array}$ \\
\hline $1+2+3+\mathbf{4}=10$ & $\begin{array}{l}4 \text { is the last } \\
\text { number and } \\
\text { from } \frac{4 x 5}{2}=10\end{array}$ & $\begin{array}{l}\text { continued with } \\
\text { the next 5 digits }\end{array}$ \\
\hline
\end{tabular}

Figure 1: Task in the learning materials: an example. 
In providing alternative ways to solve the sum problem of the first 15 integers, the teachers provides a variety of ways, as shown in figure 2.
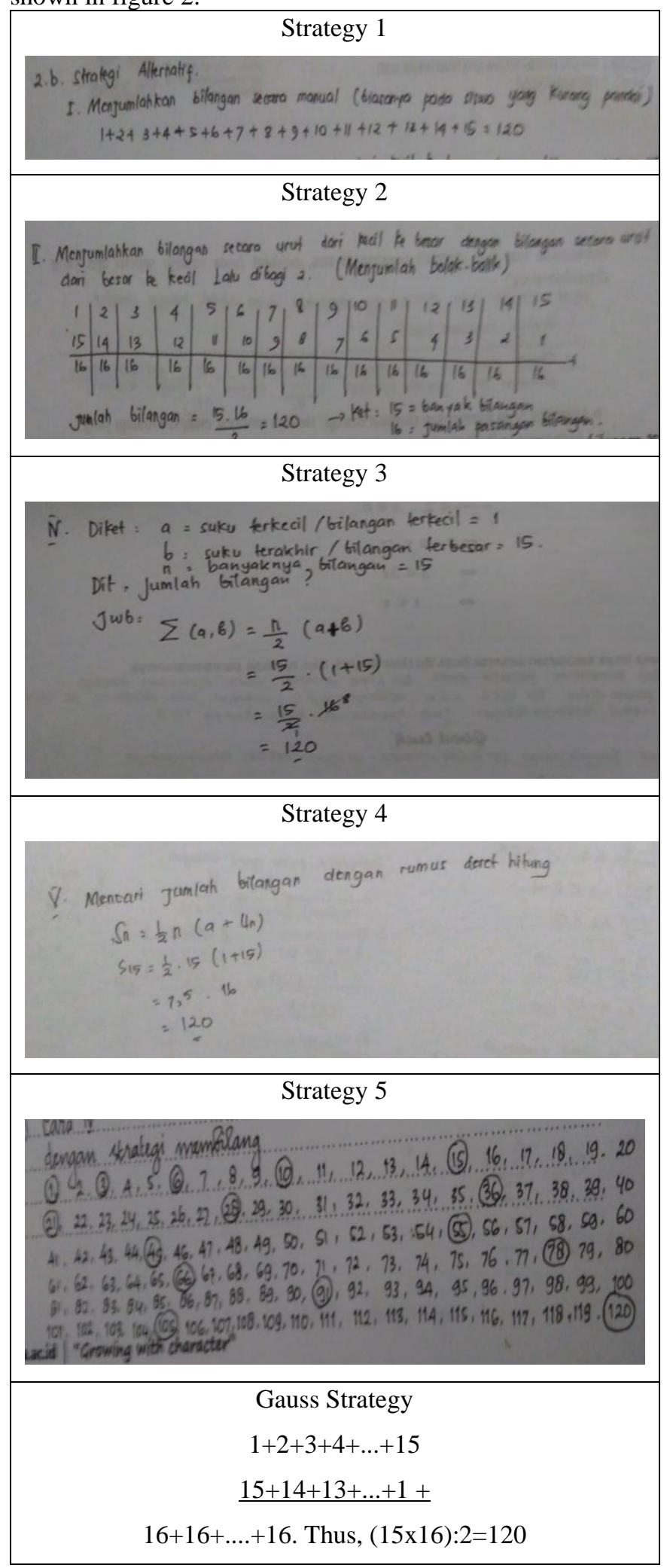

Figure 2: Examples of teachers' responses on the problem at field test stage
The figure above shows the teacher giving the strategy of the most routine (manual numbering one by one tribe) as shown by strategy 1 to the systematic and symbolic look like strategy 4 . Furthermore, the teacher is also asked to determine which strategy is most effective. An analysis of the answers to the worksheet shows that all teachers agree that the strategy shown in the question is the most effective compared to the strategies they have set. This is because the strategy is considered more simple, just look at the pattern only, without counting.

\section{DISCUSSION}

Validity of the learning materials was obtained from expert judgments on the learning materials as well as from the written comments by the experts on lesson plan and teaching book. In addition, it was also obtained from the observation of learning activities at the time of small group to examine the consistency between the teachers' activities during learning with the activities contained in teaching materials. Results indicate that lesson plan, teaching book, and worksheet in the category are very good. In addition, the observation data of small group learning observation indicates that the activities undertaken by teacher were in line with the purpose of the learning objectives in the worksheets and teaching book revised in the previous activities. Thus, the learning materials meet the aspects of validity.

Furthermore, teaching material is said to be practical if it can be used in the field according to experts and practitioners (one-to-one and expert review stage) and based on the implementation implementation of teaching materials in the classroom. The teaching material is also said to be practical if the validator states that the learning device can be used in the field with little revision or no revision, which has been filled in on the validation sheet. Based on the results of all experts, the lesson plan and the teaching book developed can be used in the field with little revision. Based on the data analysis, the implementation of learning using the teaching materials in small group, all the teachers gave positive responses and provided constructive suggestions for improvement of teaching materials. Thus, it can be concluded that the developed teaching materials meet the aspects of practicality.

The effectiveness of teaching materials is seen from the potential effects of teaching materials toward the change of teacher's type of beliefs toward mathematics and its learning, teachers's response, and teachers involvement in field test. The result of the analysis of the teachers's type of beliefs toward mathematics and its learning shows there is a change towards constructivist belief that is in line with the concept of problem solving in learning. Furthermore, analysis of teachers responses to teaching materials developed showed a positive response. These results indicate that the response of the teachers in the positive category. Based on the description, it can be concluded that the developed teaching materials meet the aspect of effectiveness.

Findings Siswono et al [12] demonstrated that teacher teaching practices of teachers in field test, even with problemsolving approach, have not fully met the requirements for problem-solving learning. However, this seems to be incompatible with the studies of Siswono et al [8] who reported 
that high school teachers in their studies tend to be convinced to apply problem-solving ideas as dynamic approaches while teaching math. Thus, the gap between teacher confidence and teacher teaching practices needs to be the focus of further concern, especially by professional developers of teachers to develop their knowledge and skills in problem-solving teaching practice. For that, Peker [13] argues that learning problemsolving needs to be done through activities such as sharing experiences and knowledge of learning, discussing with friends and instructors, discussing each other actively in small groups, and implementing problem-solving strategies in the right place and the right way. To address these challenges, Swan and Swain [14] find that through collaborative learning environments in which teachers are challenged to face adversity and take active class roles designed in teacher professional development, teacher confidence in teacher problem solving will increase.

\section{CONCLUSIONS}

To sum, the learning materials developed in this study meet the aspects of validity, practicality, and effectiveness. Validity is indicated by the experts judgements indicating that the learning materials is good to be implemented. Practicality is demonstrated by the general assessment of assessed by the teachers in one-to-one as well as expert review stage. Results of the implementation of learning using teaching materials in small groups shows that the teachers in small group stage provided positive responses and provide constructive suggestions for improvement of teaching materials. Effectiveness of the learning materials is shown by a change toward the type of constructivist belief that is aligned with the concept of problem solving in learning, the positive response of the teachers to the instructional material developed, and the active involvement of the teachers in the learning activity using the resource.

In the future studies, we encourage to develop the components of MPSKT characterizing a more complex network of interdependent knowledge among the components.

\section{ACKNOWLEDGMENT}

The following investigation was made thanks to the contributions for the research scheme of Penelitian Kebijakan Pascasarjana funded by Universitas Negeri Surabaya with contract number: 006403/UN38.8/LT/2017

\section{REFERENCES}

[1] O. Chapman, LUMAT vol.31, 2015 p19

[2] E. A. Silver, For the learning of math. vol.141, 1994, p19

[3] [3] T Plomp \& N. Nieveen, An introduction to educational design research, Proc. of the Seminar Conducted at the East China Normal University, Shanghai: SLO-Netherlands Institute for Curriculum Development, 2007

[4] [4] M. Tessmer, Planning and conducting formative evaluations: Improving the quality of education and training, US: Psychology Press, 1993

[5] [5] Z. Zulkardi, Developing a learning environment on realistic mathematics education for Indonesian student teachers, Doctoral dissertation, University of Twente Enschede, 2002

[6] [6] K. Beswick, “Math. Educ.” Res. J. vol.172, 2005, p39

[7] [7] P. Ernest, The impact of beliefs on the teaching of mathematics In P Ernest Ed Mathematics teaching: The state of the art pp 249-253, New York: Falmer, 1989.

[8] [8] T. Y. E. Siswono, A. W. Kohar, I. Kurniasari and Y. P. Astuti, J. Phys. Con. Ser. 693, 2016, 012015

[9] [9] T. Y. E. Siswono, A. W. Kohar and S. Hartono, J. Phys. Con. Ser. 812, 2017012046

[10] [10] G. Polya, How to solve it, New Jersey: Princeton University Press, 1973

[11] [11] J. Mason, LUMAT, vol.31, 2015, p101

[12] [12] T. Y. E. Siswono, A. W. Kohar and S. Hartono Southeast Asian Math Educ. J. vol.7, 2017 p27

[13] [13] M. Peker, "The New Educ". Review, vol.193, 200995

[14] [14] M. Swan and J. Swain, J. Further and High. Educ. Vol.342, 2010, p165 